\title{
The Implication of the HEQSF Act on Human and Financial Resources
}

Karel Kapp

University of Technology, Pretoria, South Africa

\begin{tabular}{l} 
ARTICLE INFO \\
\hline Keywords: \\
Higher Education \\
Qualification Sub- \\
Framework \\
Department of Higher \\
Education and Training \\
Universities of \\
Technology \\
Classification of \\
Educational Subject \\
Matter
\end{tabular}

\begin{abstract}
Currently the fee structure at a University of Technology is based on subject and not credit base. Qualifications found in the same funding category within the University showed a large variability in costs. The research seeked to understand how the alignment of the fee structure of the Higher Education Qualifications Sub Framework (HEQSF) would affect class fees at UoTs. To propose a new fee structure in a sustainable way a model was developed.

A University of Technology was used as a case study. A mixed method research design was followed in the realm of an epistemological paradigm that focusing on policy and needs analysis and on predicted future requirements. The model takes into consideration the qualification mix, funding groups, National Qualifications Framework (NQF) levels, NQF credits of the qualifications.

Benchmarking between universities indicate significant discrepancies, based on qualifications of similar duration, funding category and resources required. It showed that the UoT was much lower than the country average.

The novelty of the developed model was to calculate the total income of a qualification for each funding group. Based on classification of educational subject matter (CESM) categories, Department of Higher Education and Training (DHET) funding, Teaching Input Units (TIUs), Teaching Output Units (TOUs), the Rand value of a Senior Lecturer Equivalent (SLE), the targeted number of Full Time Equivalents (FTEs) per SLE per CESM category, TUT financial targets, and benchmarked data. Variables of the model were dynamic, implying that it could easily be adapted for changes in (DHET) funding policy.

The developed model showed the new class fee structure for all qualification types. Ring fencing of $25 \%$ between the lowest and the highest funding group was done, and the impact it has on income generated by class fees.
\end{abstract}

\section{Introduction}

Costing subjects has been lacking at the University of Technology, and for a university to go through an organisational review, all financial implications needed to be known. This makes the study unique as it shows the process followed to change the fee structure for the incoming HEQSF qualifications, instead of increasing student numbers that cannot be accommodate by the infrastructure of the University. A model was developed by using historically audited Higher Education Management Information System (HEMIS) data, to make prediction on what the effect the HEQSF qualification will have on financial and human resources. 


\section{Background}

In December 2012, the South African Minister of Higher Education and Training approved a revised Higher Education Qualifications Sub-Framework (HEQSF) (DoE, 2012). Although this aided in the establishment of a single qualifications framework for higher education in South Africa to enable the articulation between programmes and the transfer of students between different types of higher education institutions, it created a disruptive influence on the qualifications offered by universities of technology, international comparability, and industry expectations.

The Council of Higher Education (CHE) and the Department of Higher Education and Training (DHET) mandated all Higher Education Institutions to implement the new Higher Education Qualifications Sub Framework by 2020. The purpose of this research was to determine how the implementation of the Higher Education Qualifications Sub Framework would affect the financial funding and human resources in a University of Technology when fully phased in, and the National Accredited Technical Education Diploma (NATED151) fully phased out.

\section{Problem Statement}

The level of instruction on the HEQSF differs from the old NATED151 programmes, impacting financial funding and human resource requirements.

Table 1.

NATED 151 Qualifications vs HEQFS Qualification (South African Technology Network pg. 3)

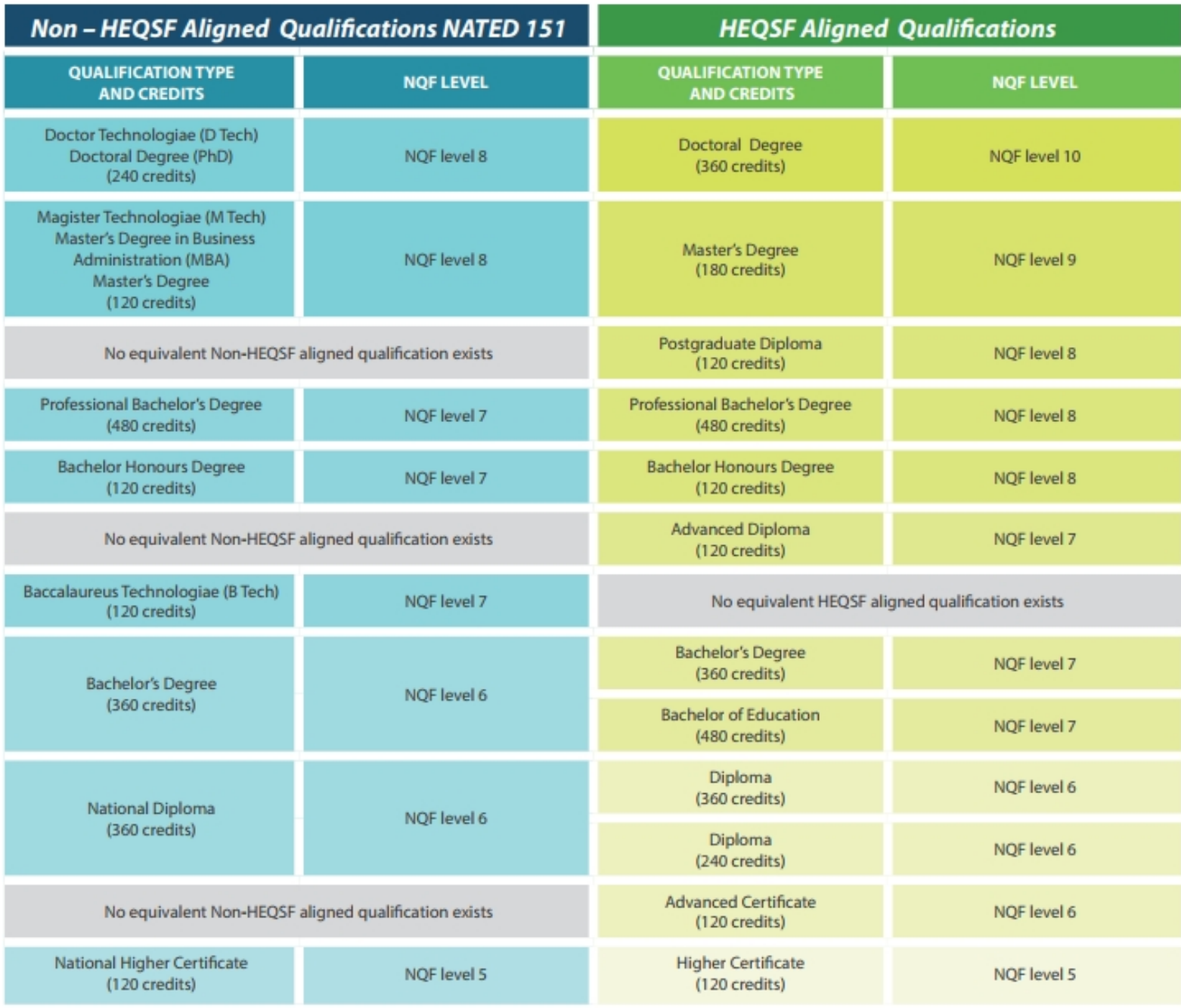


A study of the implication of the HEQSF act on human and financial resources at a University of Technology (UoT) was required to enable the effective management of the implementation process. It was therefore necessary to investigate the existing structure of the University and see how it could be streamlined to deal with the needs of the HEQSF qualifications when it will be fully implemented by 2025 .

The implication of the HEQSF act on human and financial resources would appear to be significant on Universities of Technology (UoTs). The reason for this was that the Bachelor of Technology (B.Tech) qualification which had to be phased out by 2023 was replaced with two new qualifications, namely an Advanced Diploma and a Post Graduate Diploma. This not only had implications for the university but also for the students who completed their Bachelor of Technology degree and who wanted to further their studies. These students would need to articulate to the new qualification framework. The study therefore contributed to an improved understanding of the financial funding and Human Resource requirements of a university in transition.

A further motivation for this study was based on the Executive Management Committee (EMC) decision of a University of Technology that the proportion of distributable income spent on salaries need to be reduced to align expenditure to the national average, namely $55 \%-62.5 \%$ of total income. In addition, that $60 \%$ of the $62.5 \%$ should be allocated to the academic project and $40 \%$ to the support staff (TUT, 2017). This implies looking at the current fee structure for the NATED 151 qualification, and calculate how viable the fees are for the HEQSF qualifications being introduced.

Questions that needed to be answered by the investigation:

How does the implementation of the HEQSF influence Human Resources in a University of Technology?

How does the implementation of the HEQSF influence Funding Resources in a University of Technology?

In addition, how can the student enrolment plan be linked to the HEQSF for sustained financial viability?

\section{Theoretical and Policy Framework}

The National Implementation Research Network Framework would frame this research. This framework was suitable for my study in that it provided a sound foundation for the exploration, purposeful selection, clarification, improvement, and systematic implementation of a programme's practice model (Fixen, Naoom, Blase, Friedman, \& Wallace, 2005). The intervention component framework includes the following:

- Elements and activities created to improved outcomes for the target field of interest.

- Analysis of the Higher Education Qualifications Sub Framework in reference to the policy of the Council on Higher Education and Training implementation plan.

- Existing data gathered from official documents and Higher Education Information Management System (HEMIS) data. The data provided financial planning, implementation procedures of the policy for stakeholders to do strategic planning and developing of enrolment plans

- Alternative models where developed and tested which would best be implemented with the least amount of disruption to the university

\section{Method}

The epistemological paradigm that framed this research was positivism (Muijs, 2013). This paradigm was selected in order to study the implications of the Higher Education Qualification Sub-Framework Act (HEQSF) on financial and Human Resources. These implications may be 
uncovered through the analysis of relevant existing data. Reliable analysis methods would be utilized making the researcher as objective as possible (Muijs, 2013).

The study followed a mixed method research approach with the dominant approach being quantitative in nature. This research made use of numerical data obtained from the University of Technology. The data was processed in a systematic and objective manner in order to find generalizability within the phenomenon under investigation (Maree \& Pietersen, 2014). The qualitative element of this study speaks to the interpretation of the data collected as the data was analysed by myself. As the main objective of research is to gain valuable information from data gathered, an element of qualitative research is applicable to this study as data was used to gain insight into the impact of the Higher Education Qualification Sub-Framework (Nieuwenhuis, 2016).

The Higher Education Management Information System (HEMIS) office fulfils the University's statutory requirements in terms of the provision of information on students to the Department of Higher Education and Training (DHET) for funding purposes.

Within the predominantly quantitative research approach, the predictive analytics design was utilized. This design, as described by Waller and Fawcett (2013), is unique from all other quantitative research designs as this design is both quantitative and qualitative. This feature of a predictive analytics design makes it perfect for this study.

This design forecasts possible outcomes while looking to the past and analysing those outcomes for an outcome other than what has already occurred. Predictive analytics seeks to identify relationships between variables by using mathematical methods (Waller \& Fawcett, 2013).

Conclusions are drawn both efficiently and cost-effectively. Within a predictive analysis design, logistics and supply chain predictive analytics are present. Supply chain predictive analytics is most applicable to this study as it is defined as using both quantitative and qualitative methods to improve attractiveness through the estimation of past and future levels of integration of business processes among tasks or establishments. An estimated cost and service level is calculated within this design (Waller \& Fawcett, 2013).

The documents that was analysed included data supplied by the registrar of the University. This dataset was specific to the university. These datasets are simply presented as set of numbers, which speak to the student to lecturer ratio, student graduation ratio, first time entering students, full time equivalent numbers, and headcounts of students in specific programmes. With these data inputs, I developed a model for which these numbers could be interpreted meaningfully, thus further justifying the use of the mixed methods research approach as quantifiable numbers will be analysed for meaning by myself.

I utilized this data as a departing point in developing a new model to make predictions. With the new designed model, Full Time Equivalent (FTE's), First Time Entering Number (FTEN's), graduation numbers and headcount numbers were used to calculate averages and ratios based on historical data.

By using funding categories, amount of credits, level of instruction as external variables, calculations and predictions were made to determine future programme needs depending on the number of students enrolling. Those predications included total income, cost, staff needs, staff to student ratios, etc.

\section{Findings}

Benchmarking was done through the office of the registrar at the University of Technology with the majority of South African universities. These universities included traditional universities that deliver similar qualifications such as Stellenbosch University, University of Pretoria, and Northwest University. It also included Universities of Technologies, such as Durban University of Technology, Vaal University of Technology, Central University of Technology, Cape Peninsula University of Technology and Walter Sisulu University of 
Technology and Science, based on qualifications of similar duration, funding category and resources required. The results are shown in Figures 1 and 2. Again, significant discrepancies are observed. For example, a diploma in the Faculty of the Arts the lowest class fees can be seen as R 25000 per year, and the highest as R53 000 per year. With all the universities taken into consideration (traditional and UoTs) a National Average was calculated as R 41000 , in general, the University of Technology was much lower than the country average coming in at R35 500. This trend can be observed through all the undergraduate qualifications through the faculties

The same discrepancies could be seen when benchmarking was done with the PG Diploma, Honours, and Baccalaureus Technologiae qualifications. For example, in the Faculty of the Arts the lowest class fees can be seen as R 10000 per year, and the highest as R44 000 per year. With all the universities taken into consideration (traditional and UoTs) a National Average was calculated as R 28 000, in general, the University of Technology is much lower than the country average coming in at R13 553.

With the benchmarking done, the need was there for the University of Technology to revise the fee structure, as the current fee structure was not financially viable for the survival of the university and the current staff profile. This would be the only opportunity to introduce a credit base fee structure with the phasing in of the HEQSF aligned qualifications as most programmes was new to the University. In addition, to re aligned the distributable income received for human resources.

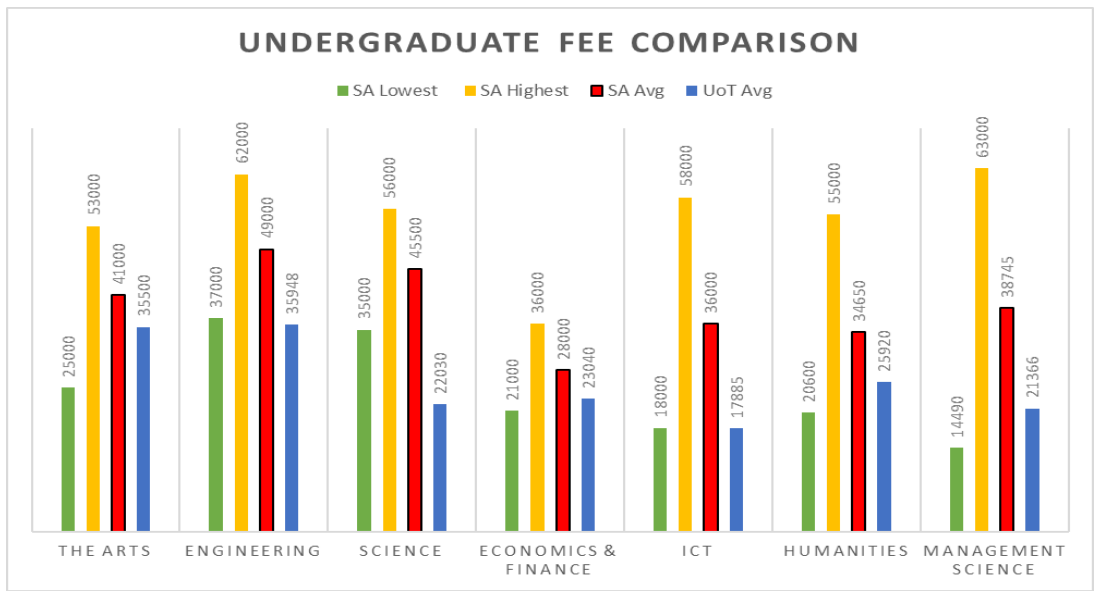

Figure 1. Undergraduate Fee Comparison Benchmarking (Industry Survey: SA lowest / SA highest / SA average / UoT)

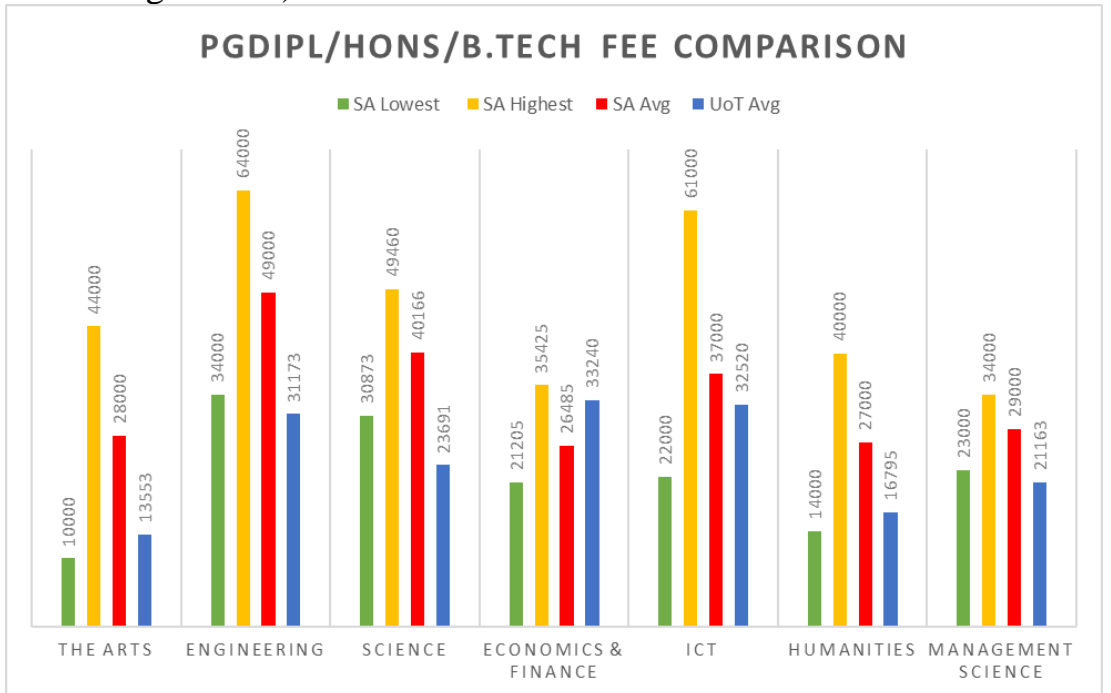

Figure 2. PG Diploma / Honours/ Baccalaureus Technologiae Fee Comparison Benchmarking (Industry Survey: SA lowest / SA highest / SA average / UoT) 


\section{Conclusion}

After assessing the facilities of the University of Technology, it was confirmed that current infrastructure could not accommodate the required increase in student enrolment during the HEQSF phasing in period. Against this logistical limitation, it was recommended by the University of Technology at a strategic management meeting held in April 2017 that a revised fee structure for HEQSF-aligned qualifications be approved for implementation 2019. This recommendation only applied to HEQSF aligned qualifications, not existing (phasing out) NATED qualifications.

The processed that was followed was to get approval from all Faculty Committees for Teaching and Learnings (FCTL) from all Faculties in the University, after it had to serve at an Executive Management Committee (EMC), approval at the EMC followed with Senate, and lastly Council that met 8 December 2018.

\subsection{Adopted Principles}

After several in depth discussions, analysis and a fee structure workshop involving key stakeholders from Support Management Systems, finances, executive deans, and other stakeholders, a new fee structure for the UoT was proposed based on the following principles:

- Class fees for a module or subject should be linked to the number of HEQSF credits.

- Proposed class fees for HEQSF-aligned qualifications should not be lower than the cost for similar NATED qualification(s) currently offered.

- Proposed annual fees should be comparable with industry average for similar qualifications or qualifications of similar duration/credits.

- Class fees should be modelled to contribute towards the Executive Management Committee's (EMC) goal to allocate $62.5 \%$ of distributable income to salaries, with $60 \%$ of the $62.5 \%$ for the academic project.

- Class fees should align with the DHET funding categories and targeted SLE:FTE ratios

\subsection{Financial Prediction Model}

The Financial Prediction model was developed by calculating the total income based on CESM categories, DHET funding, Teaching Input Units (TIUs), Teaching Output Units (TOUs), Research output Units (ROUs), class fees and the Rand value of a Senior Lecturer Equivalent (SLE), the targeted number of Full Time Equivalents (FTEs) per SLE per CESM category, UoT financial targets, and benchmarked data. The variables of the model are dynamic, implying that it can be easily adapted for changes in DHET funding policy.

Below are extracts from the prediction model, it was built using Microsoft excel with formulas embedded into the sheet.

Figure 3 shows the current rand value for 2019, for an SLE, TIU, TOU and ROU, for year 2020-2025 the average increase was used over the last three years to predict what the rand values will be using the average yearly increase as shown for each variable.

Figure 4 shows which area of study resides in which funding group, (CESM categories), these funding groups are from number 1 to number 4, with each having his own weighting for funding, whether its undergraduate, honours, masters or doctorates. Thes are shown as input funding weights, when a student starts with his qualification, and graduate funding or teaching output, research output as output funding. 


\begin{tabular}{|c|c|c|c|c|c|c|c|}
\hline \multicolumn{8}{|c|}{ External Variables } \\
\hline \multirow{2}{*}{\begin{tabular}{|l|}
$\begin{array}{l}\text { SLE Rand } \\
\text { value }\end{array}$ \\
R10 985,00 \\
\end{tabular}} & \multicolumn{2}{|c|}{ TIU Rand Value } & \multicolumn{2}{|c|}{ TOU Rand Value } & \multicolumn{2}{|c|}{ ROU Rand Value } & \multirow{2}{*}{\begin{tabular}{|l|} 
Year \\
2019
\end{tabular}} \\
\hline & $R$ & 14773,78 & $\mathbf{R}$ & 30344,11 & $R$ & 121871,72 & \\
\hline R11 753,95 & R & 16103,42 & R & 34288,84 & $R$ & 129184,02 & 2020 \\
\hline R12 576,73 & R & 17552,73 & R & 38746,39 & $R$ & 136935,06 & 2021 \\
\hline R13 457,10 & R & 19132,47 & R & 43783,43 & $R$ & 145151,17 & 2022 \\
\hline R14 399,09 & $R$ & 20854,40 & R & 49475,27 & $R$ & 153860,24 & 2023 \\
\hline R15 407,03 & $R$ & 22731,29 & $R$ & 55 907,06 & $R$ & 163091,85 & 2024 \\
\hline R16 485,52 & $R$ & 24777,11 & $\mathbf{R}$ & 63174,97 & $R$ & 172877,36 & 2025 \\
\hline
\end{tabular}

\begin{tabular}{|l|r|}
\hline Yearly salary \% increase & $7 \%$ \\
Avg Yearly DHET (TIU) funding \% incre & $9 \%$ \\
\hline Avg Yearly DHET (TOU) funding \% incre & $13 \%$ \\
\hline Avg Yearly DHET (ROU) funding \% incre & $6 \%$ \\
\hline Yearly fee \% increase & $5 \%$ \\
\hline
\end{tabular}

Figure 3. External Variables and predicted increase from 2019 to 2025

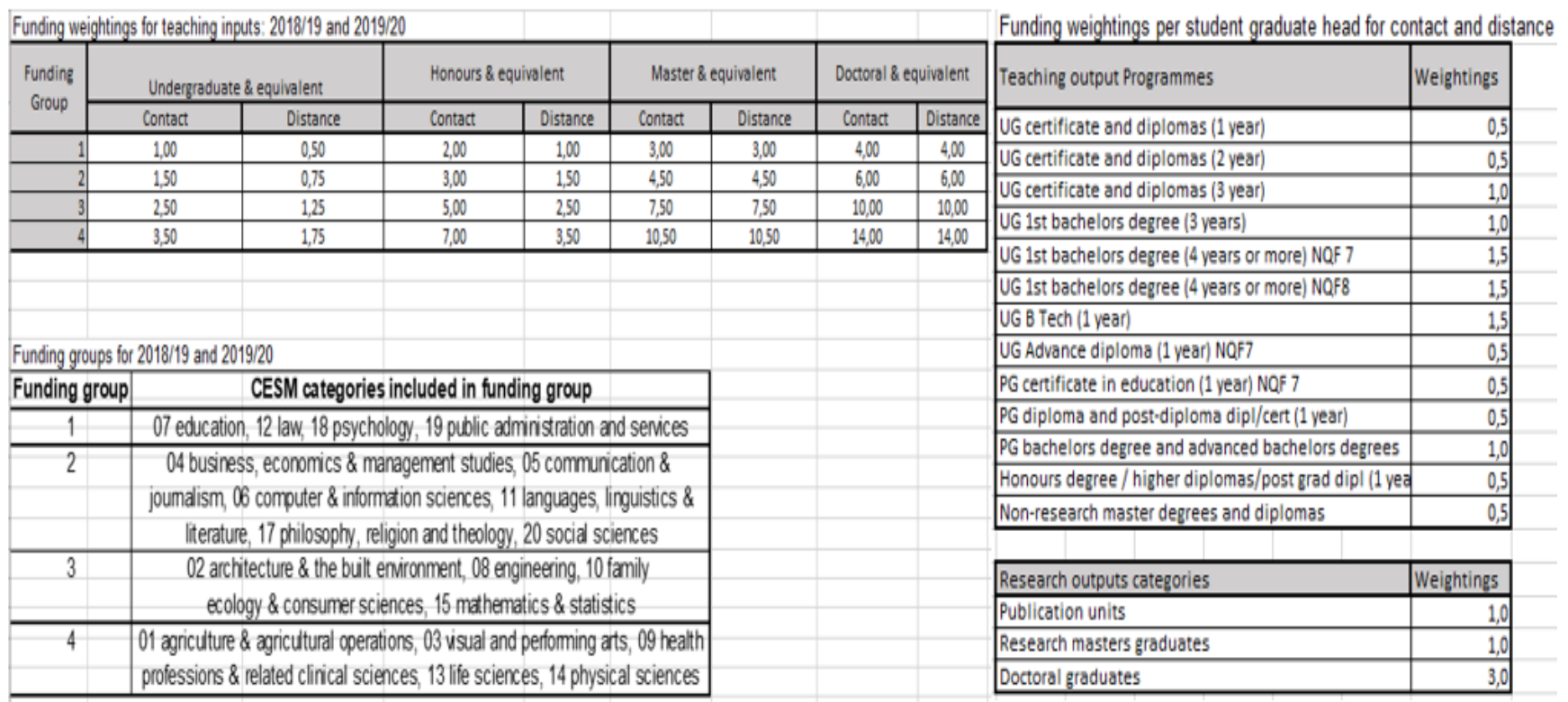

Figure 4. Funding weights for teaching input, teaching outputs, and CESM categories for 2018 to 2020

Figure 5 is an extract of a completed faculty (Faculty of Engineering and the Built Environment) with all its different NQF level of qualifications, headcounts, FTEs, Graduates, FTE ratios and Graduation ratios for the last three audit data years. With the two ratios, prediction could be made based on past history, namely a predicted headcount, predicted FTE and predicted graduate numbers. With these predicted numbers income generated by TIUs, TOUs and class fees could be calculated, by using formulas in each tab, linking to the monitory values of the external variables to the faculty data sheet.

As example in 2025 income: A undergraduate $1^{\text {st }}$ bachelors degree qualification (360 credit) in Engineering. This qualifications resides as 08 CESM category, and falls in funding group 3. Thus the funding weight for a TIU is 2.50 for contact. The TOU weight is 1.0 (figure 4). Government funding lacks two years, so to calculted TIUs and TOUs the values of 2023 need to be taken into consideration. The monitary value for a TIU in 2023 would be R $20,845.40$ if the growth stays constant at $9 \%$. For a TOU in 2023, R 49, 475.27 if growht stays at 13\%, and for class fee R456 per credit if increase by $5 \%$ per year until 2025 (figure 3). 
TIU income $=$ FTE $\mathrm{x}$ TIU rand value

$=1885 \times \mathrm{R} 20,845.40$

$=\mathbf{R ~ 9 8 , 2 7 4 7 8 2 . 0 1}$

TOU income $=$ Graduates $\mathrm{x}$ TOU rand value

$=651 \times \mathrm{R} 49,475.27$

$=\mathbf{R} 48,320678.70$

Class Fees =FTE $\mathrm{x}$ Value per credit $\mathrm{x}$ credit per year

$=2029 \times \mathrm{R} 341 \times 120$

$=\mathbf{R} 111,1541452.06$

Total Income generated by the qualification

$$
\begin{aligned}
& =\mathrm{R} 98,274782.01+\mathrm{R} 48,320678.70+\mathrm{R} 111,1541452.06 \\
& =\mathbf{R} 257, \mathbf{7 4 9 9 1 2 . 7 7}
\end{aligned}
$$

This can be done for all qualifications as shown in figure 1.4 ending up with a projected total income generated by the Faculty in this case $\underline{\mathbf{R} 753, \mathbf{5 0 1} \mathbf{5 8 4 . 3 3}}$.

From this only $60 \%$ of $65 \%$ of the projected income can be used in the Faculty for salaries, this includes academics, administration and technical staff as shown in figure 6 .

\section{$=\mathbf{R} 293,865617.89$}

The specific UoT uses SLEs to determine the amount of staff needed, 100 SLEs is equivalent to 1 Senior lecturer.

Thus, to calculate the amount of SLEs generated by the distributable income is:

SLEs $\quad=$ Salary income $/$ SLE value

$$
\begin{aligned}
& =\mathrm{R} 293,865617.89 / \mathrm{R} 16,484.40 \\
& =\mathbf{1 7 ~ 8 2 6}
\end{aligned}
$$

This means the faculty will only receive the above amount of SLE's to run all of its qualifications.
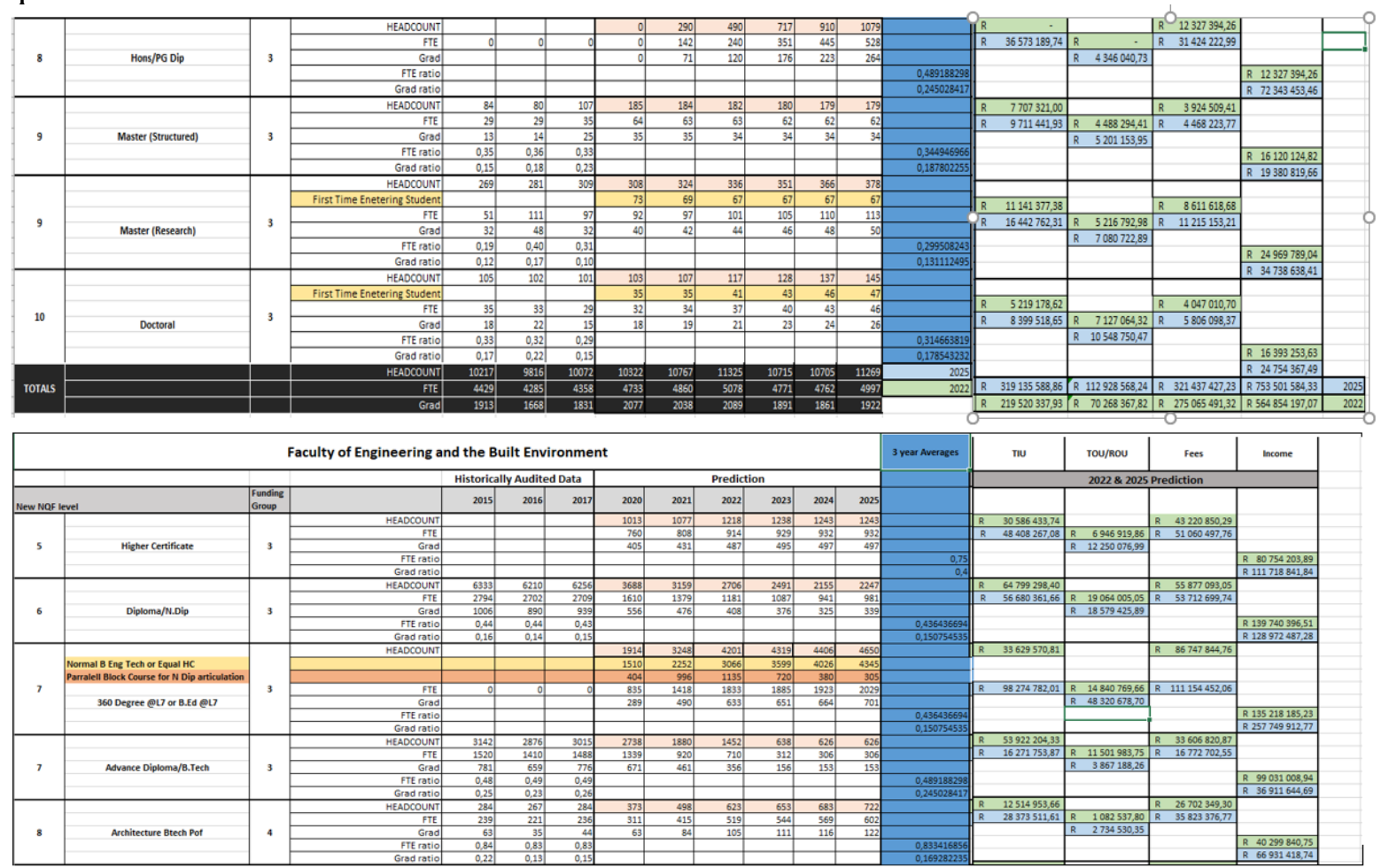

Figure 5. Faculty of Engineering and the Built Environment detailed income generation for the period of 2020 - 2025 per NQF level qualification and projected headcount, FTE and Graduates 


\begin{tabular}{|l|r|rr|}
\hline \multirow{3}{*}{2025} & $60 \%$ of $65 \%$ of Projected Income 2025 & R & 293865617,89 \\
\cline { 2 - 4 } & SLEs $(60 \%$ Of $65 \%$ of projected income $)$ & & 17826 \\
\cline { 2 - 4 } & & \\
\cline { 2 - 4 } & & \\
\hline
\end{tabular}

Figure 6. Distributable income percentages that can be used for salaries of the projected income in 2025

\subsection{Proposed Fee Structure}

Table 1 shows the consensus reached for the credit-based fee structure held at the Academic Leadership Programme Workshop 26 September 2018 at Toppieshoek for the cost per year for all undergraduate qualifications (level 5-7 and L8). The attendance of the Vice Chancellor, Deputy Vice Chancellors, Executive Deans from all faculties, professors of the university, strategic management and support directors, human resources directors and financial aid directors were all present at the workshop. Moreover, consensus was reached on the viability of the model and the predictions made.

Table 1.

Proposed cost per credit for HEQSF aligned qualifications

\begin{tabular}{|c|c|c|c|c|c|c|c|c|c|c|}
\hline Qualification Type & $\begin{array}{l}\text { Funding } \\
\text { Group }\end{array}$ & $\begin{array}{l}\text { NQF } \\
\text { Level }\end{array}$ & Str_Res & NQF Credits & $\begin{array}{l}\text { Cost Per } \\
\text { Credit } \\
\text { Contact }\end{array}$ & $\begin{array}{l}\text { Cost Per Credit } \\
\text { Distance }\end{array}$ & & $\begin{array}{l}\text { ication } \\
\text { istance }\end{array}$ & $\begin{array}{l}\text { Qualification } \\
\text { Cost Contact }\end{array}$ & $\begin{array}{l}\text { Qualification } \\
\text { Cost Contact } \\
\text { per annum }\end{array}$ \\
\hline Certificate & 1 & 5 & Structured & 120 & R280 & R140 & $\mathrm{R}$ & 16,829 & R33,659 & $R 33,659$ \\
\hline Higher Certificate & 1 & 5 & Structured & 120 & $\mathrm{R} 280$ & R140 & $\mathrm{R}$ & 16,829 & R33,659 & R33,659 \\
\hline Advanced Certificate & 1 & 6 & Structured & 120 & $\mathrm{R} 280$ & R140 & $\mathrm{R}$ & 16,829 & R33,659 & R33,659 \\
\hline Diploma & 1 & 6 & Structured & 360 & R280 & R140 & $\mathrm{R}$ & 50,488 & R100,976 & R33,659 \\
\hline Advanced Diploma & 1 & 7 & Structured & 120 & $\mathrm{R} 280$ & R140 & $\mathrm{R}$ & 16,829 & R33,659 & R33,659 \\
\hline Bachelor Degree -360 & 1 & 7 & Structured & 360 & R280 & R140 & $\mathrm{R}$ & 50,488 & R100,976 & R33,659 \\
\hline Prof Bachelor Deg - 360 & 1 & 7 & Structured & 360 & R280 & R140 & $\mathrm{R}$ & 50,488 & R100,976 & R33,659 \\
\hline Bachelor Degree-480 & 1 & 8 & Structured & 480 & R305 & R152 & $\mathrm{R}$ & 73,171 & R146,342 & R36,586 \\
\hline Prof Bachelor Deg-480 & 1 & 8 & Structured & 480 & R305 & R152 & $\mathrm{R}$ & 73,171 & R146,342 & R36,586 \\
\hline Masters Deg-Structured & 1 & 9 & Structured & 180 & $\mathrm{R} 260$ & $\mathrm{R} 130$ & $\mathrm{R}$ & 23,400 & R46,800 & $\mathbf{R 4 6 , 8 0 0}$ \\
\hline Certificate & 2 & 5 & Structured & 120 & R301 & R150 & $\mathrm{R}$ & 18,031 & R36,063 & R36,063 \\
\hline Higher Certificate & 2 & 5 & Structured & 120 & R301 & R150 & $\mathrm{R}$ & 18,031 & R36,063 & R36,063 \\
\hline Advanced Certificate & 2 & 6 & Structured & 120 & R301 & $\mathrm{R} 150$ & $\mathrm{R}$ & 18,031 & R36,063 & R36,063 \\
\hline Diploma & 2 & 6 & Structured & 360 & R301 & R150 & $\mathrm{R}$ & 54,094 & R108,188 & R36,063 \\
\hline Advanced Diploma & 2 & 7 & Structured & 120 & R301 & R150 & $\mathrm{R}$ & 18,031 & R36,063 & R36,063 \\
\hline Bachelor Degree - 360 & 2 & 7 & Structured & 360 & R301 & R150 & $\mathrm{R}$ & 54,094 & R108,188 & R36,063 \\
\hline Prof Bachelor Deg -360 & 2 & 7 & Structured & 360 & R301 & R150 & $\mathrm{R}$ & 54,094 & R108,188 & R36,063 \\
\hline Bachelor Degree-480 & 2 & 8 & Structured & 480 & R327 & R163 & $\mathrm{R}$ & 78,398 & R156,795 & R39,199 \\
\hline Prof Bachelor Deg-480 & 2 & 8 & Structured & 480 & R327 & R163 & $\mathrm{R}$ & 78,398 & R156,795 & R39,199 \\
\hline Masters Deg-Structured & 2 & 9 & Structured & 180 & R275 & R138 & $\mathrm{R}$ & 24,750 & R49,500 & R49,500 \\
\hline Certificate & 3 & 5 & Structured & 120 & R341 & R170 & $\mathrm{R}$ & 20,436 & $\mathbf{R 4 0 , 8 7 1}$ & $\mathbf{R 4 0 , 8 7 1}$ \\
\hline Higher Certificate (120) & 3 & 5 & Structured & 120 & R341 & R170 & $R$ & 20,436 & R40,871 & R40,871 \\
\hline Higher Certificate (140) & 3 & 5 & Structured & 140 & R292 & R146 & $\mathrm{R}$ & 20,440 & R40,880 & R40,880 \\
\hline Advanced Certificate & 3 & 6 & Structured & 120 & R341 & R170 & $\mathrm{R}$ & 20,436 & R40,871 & $\mathbf{R} 40,871$ \\
\hline Diploma & 3 & 6 & Structured & 360 & R341 & R170 & $\mathrm{R}$ & 61,307 & R122,613 & R40,871 \\
\hline Advanced Diploma & 3 & 7 & Structured & 120 & R341 & $\mathrm{R} 170$ & $\mathrm{R}$ & 20,436 & R40,871 & R40,871 \\
\hline Bachelor Degree - 360 & 3 & 7 & Structured & 360 & R341 & $\mathrm{R} 170$ & $\mathrm{R}$ & 61,307 & R122,613 & R40,871 \\
\hline Prof Bachelor Deg - 360 & 3 & 7 & Structured & 360 & R341 & R170 & $\mathrm{R}$ & 61,307 & R122,613 & $\mathbf{R} 40,871$ \\
\hline $\begin{array}{l}\text { Prof Bachelor Degree - } \\
\text { 3year }\end{array}$ & 3 & 7 & Structured & 420 & R292 & R146 & $\mathrm{R}$ & 61,320 & R122,640 & $\mathbf{R 4 0 , 8 8 0}$ \\
\hline Bachelor Degree-480 & 3 & 8 & Structured & 480 & R370 & R185 & $\mathrm{R}$ & 88,851 & R177,702 & $\mathbf{R 4 4 , 4 2 5}$ \\
\hline Prof Bachelor Deg-480 & 3 & 8 & Structured & 480 & R370 & R185 & $\mathrm{R}$ & 88,851 & R177,702 & $\mathbf{R 4 4 , 4 2 5}$ \\
\hline Masters Deg-Structured & 3 & 9 & Structured & 180 & R300 & R150 & $\mathrm{R}$ & 27,000 & R54,000 & R54,000 \\
\hline Certificate & 4 & 5 & Structured & 120 & R361 & R180 & $\mathrm{R}$ & 21,638 & $\mathbf{R 4 3 , 2 7 5}$ & $\mathbf{R 4 3 , 2 7 5}$ \\
\hline Higher Certificate & 4 & 5 & Structured & 120 & R361 & $\mathrm{R} 180$ & $\mathrm{R}$ & 21,638 & $\mathbf{R 4 3 , 2 7 5}$ & $\mathbf{R 4 3 , 2 7 5}$ \\
\hline Advanced Certificate & 4 & 6 & Structured & 120 & R361 & R180 & $\mathrm{R}$ & 21,638 & $R 43,275$ & $\mathbf{R 4 3 , 2 7 5}$ \\
\hline Diploma & 4 & 6 & Structured & 360 & R361 & $\mathrm{R} 180$ & $\mathrm{R}$ & 64,913 & R129,826 & $\mathbf{R 4 3 , 2 7 5}$ \\
\hline Advanced Diploma & 4 & 7 & Structured & 120 & R361 & R180 & $\mathrm{R}$ & 21,638 & R43,275 & $\mathbf{R 4 3 , 2 7 5}$ \\
\hline Bachelor Degree -360 & 4 & 7 & Structured & 360 & R361 & R180 & $\mathrm{R}$ & 64,913 & R129,826 & $\mathbf{R 4 3 , 2 7 5}$ \\
\hline Prof Bachelor Deg - 360 & 4 & 7 & Structured & 360 & R361 & R180 & $R$ & 64,913 & R129,826 & $\mathbf{R 4 3 , 2 7 5}$ \\
\hline
\end{tabular}




\begin{tabular}{|c|c|c|c|c|c|c|c|c|c|c|c|}
\hline Bachelor Degree-480 & \multicolumn{2}{|l|}{4} & 8 & Structured & 480 & R392 & \multicolumn{2}{|l|}{ R196 } & 94,077 & R188,155 & R47,039 \\
\hline Prof Bachelor Deg-480 & \multicolumn{2}{|l|}{4} & 8 & Structured & 480 & R392 & \multicolumn{2}{|l|}{ R196 } & 94,077 & R188,155 & R47,039 \\
\hline Masters Deg-Structured & \multicolumn{2}{|l|}{4} & \multicolumn{2}{|r|}{ Structured } & 180 & R317 & \multicolumn{2}{|l|}{ R159 } & 28,530 & R57,060 & R57,060 \\
\hline \multicolumn{12}{|l|}{ Specialised Qualifications } \\
\hline MBA & 2 & 9 & & Structured & 180 & R611 & N/A & N/A & & R109, 980 & R109, 980 \\
\hline $\begin{array}{l}\text { DIPLOMA IN } \\
\text { INDUSTRIAL PHYSICS }\end{array}$ & 3 & 6 & & Structured & 400 & R152 & N/A & N/A & & R60, 800 & R18, 240 \\
\hline $\begin{array}{l}\text { BACHELOR OF } \\
\text { PHARMACY }\end{array}$ & 4 & 7 & & Structured & 480 & R413 & N/A & N/A & & R198, 240 & R49, 560 \\
\hline $\begin{array}{l}\text { BACHELOR OF } \\
\text { ENVIRONMENTAL } \\
\text { HEALTH }\end{array}$ & 4 & 7 & & Structured & 500 & R247 & N/A & N/A & & R123, 500 & R29, 640 \\
\hline
\end{tabular}

The fee structure for undergraduate programmes as shown in Table 1 is divide according to Qualification Types, Funding Groups, NQF Levels, NQF Credits, Cost Per Credit Contact, Cost Per Credit Distance, Qualification Cost, Distance Qualification Cost, Contact Qualification and Cost Contact Per Annum. To illustrate the table a 360 credit NQF level six Diploma (full time offering) in funding group three will cost R122 613. The yearly class fee will be R40 871 that relates to R341 per credit. Whereas a 360 credit NQF level six Diploma (full time offering) in funding group one will cost R100 976. The yearly class fee will be R33 659 that relates to R280 per credit.

According to the proposal, the fee-structures of research-based Masters and Doctoral degrees would stay as is. However, specialised taught Masters, such as the MBA, M. Arch (Professional), M.Eng (Engineering Management) were allocated custom values based on industry average.

\subsection{Value and Limitations of The Study}

This study was limited because it was based on past HEMIS data of the University of Technology. As this study primarily relied on this data, greater inferences cannot be made or generalized to other faculties of this university or other Universities of Technology. However, the prediction model could be applied to any other university, based on the HEMIS data specific to those universities. This research is significant as it can be utilized as a tool to aid any university to structure their lecture to student ratios in order for the university to operate optimally. The prediction model can be used as a computerized "live" model and so be updated on an annual basis to give a more accurate prediction of funding and human resource needs of individual faculties and universities a whole.

\subsection{Suggestions for Further Research}

The research was conducted with the mind-set of a bottom up approach, taking into consideration all qualifications in in the university, linking it to the student enrolment plan of each Faculty and cross checking it with historical data of similar qualifications offered. Funding from the Department of Higher Education and Training was incorporated in the model, along with external variables as discussed in previous chapters. However, a top to bottom approach is definitely a further research suggestion as to test the viability of the prediction model looking at the FTE: SLE ratios specified by the Department of Higher Education and Training to income generated on levels of qualifications.

\subsection{Concluding Remarks}

This research tested me as a researcher and showed a flaw in the system of allocating class fees, basing it on credits of a qualification or subject rather than on semester or year subjects' offerings. It showed that with the phasing in of the HEQSF qualifications that a close look will 
have to be taken into consideration at the student enrolment plan for the Faculty as income generated that can be used for human resources is much less than anticipated based on the NATED 151 phasing out qualification. The research showed that the if the Faculty does not manage the process, the impact on human resources could be catastrophic during the phasing out of the NATED151 programmes and phasing in of the HEQSF aligned qualification.

\section{References}

CHE. (2004). Criteria for Programme Accreditattion. Council on Higher Education.

CHE. (2015). A new Funding Framework: How Goverment Grants are Allocated to Public Higher Education. Council on Higher Education.

DoE. (05 October 2012). National Gazette No: 30353 Vol 508. Department of Education.

Fixen, D. L., Naoom, S. F., Blase, K. A., Friedman, R. M., \& Wallace, F. (2005). Implemtation Research: A Synthesis of Literature. Florida: Louis de la Parte Florida Mental Health Institution.

HESA. (Nov 2014). Remuneration of Academuc staff at South African Universities: Asummary report of the HESA Statistical Study of Academic Remuneration. Higher Education South Africa.

Maree, K., \& Pietersen, J. (2014). The quantitative research approach. In K. Maree, First Steps in Research (pp. 144-148). Pretoria: Van Schaik.

Muijs, D. (2013). Introduction to Quantitative Research. In Doing Quantitative Research in Education with SPSS (pp. 1-10). London: SAGE Publications Ltd.

Nieuwenhuis, J. (2016). Qualitative research designs and data gathering techniques. In K. Maree (Ed.), First Steps in Research (Fifteenth Impression ed., pp. 70-93). Pretoria: Van Schaik.

TUT. (2017). Council Meeting Minutes. Tshwane University of Technology.

Waller, M. A., \& Fawcett, S. E. (2013). Data Science, Predictive Analytics, and Big Data: A Revolution That Will Transform Supply Chain Design and Management. Journal od Business Logistics, 34(2), 77-84. 